\title{
CIDADE E VIOLENNCIA NO CERRADO GOIANO: UMA LEITURA DE HERANÇA DE SANGUE, DE IVAN SANT'ANNA
}

\author{
Leonardo José Rodrigues ${ }^{1}$ \\ Ewerton de Freitas Ignácio ${ }^{2}$
}

\begin{abstract}
Resumo: Este trabalho tem por finalidade realizar uma leitura do romance Herança de sangue: um faroeste brasileiro (2012), de Ivan Sant'Anna, e divide-se em duas seções principais: na primeira, discorremos sobre o espaço urbano enquanto texto cujos significados são complexos e intricados, e sobre como esse espaço é configurado no romance, já que se emaranha com a violência que plasma interações humanas e sociais; na segunda, empreendemos uma leitura dos modos pelos quais essas interações são trabalhadas no contexto narrativo da obra. Para tanto, recorremos ao aporte teórico e crítico de estudiosos cujas obras versam tanto sobre o urbano (BARTHES, 1987; CALVINO, 1990; GOMES, 1994), quanto sobre violência (CAMPOS, 1987; OLIVEIRA, 2012; SILVA, 2014). Baseando-nos na categoria da violência, elemento constituinte da narrativa enfocada, procuramos investigar como esta se instaura como elemento intrínseco, afetando o texto ao mesmo tempo em lhe plasma o conteúdo e a forma, buscando, ainda, evidenciar que se tem, no romance em tela, a cristalização de episódios violentos, pautados sob a égide da crueldade e da intolerância, associados à crônica histórica da cidade goiana de Catalão. Palavras-chave: Cidade; Violência; Literatura goiana; História urbana.
\end{abstract}

Abstract: The purpose of this paper is to read the novel Herança de sangue: um faroeste brasileiro (2012), by Ivan Sant'Anna, and it is divided into two main sections: in the first, we discuss urban space as a text whose meanings are complex. and intricate, and how this space is shaped in the novel, as it is entangled with the violence that shapes human and social interactions; in the second, we undertake a reading of the ways in which these interactions are worked out in the narrative context of Herança de sangue. To this end, we resort to the theoretical and critical support of scholars whose works deal with both urban (BARTHES, 1987; CALVINO, 1990; GOMES, 1994), as well as about violence (CAMPOS, 1987; OLIVEIRA, 2012; SILVA, 2014). Based on the category of violence, the constituent element of the focused narrative, we seek to investigate how it is established as an intrinsic element, affecting the text at the same time in its content and form, and also seeking to show that there is, in the novel. on screen, the crystallization of violent episodes, based on the aegis of cruelty and intolerance, associated with the chronicle of the history of the city of Catalão, Goiás.

Key-words: City; Violence; Goiás literature; Urban history.

1 Mestrando em Ciências Sociais e Humanidades pelo Programa de Pós-Graduação em Territórios e Expressões Culturais do Cerrado, da Universidade Estadual de Goiás, Campus Anápolis de Ciências Socioeconômicas e Humanas. E-mail: leonardojoserodrigues123@gmail.com

2 Professor titular da Universidade Estadual de Goiás/Anápolis, onde atua junto ao PPGSS TECCER (Territórios e Expressões Culturais do Cerrado).E-mail: ewertondefreitas@uol.com.br 


\section{INTRODUÇÃO}

Em seu romance Herança de sangue: um faroeste brasileiro (2012) Ivan Sant'anna resgata episódios violentos da história da cidade goiana de Catalão, cujo contexto, do século XIX até meados do século XX, era permeado por chacinas, crimes perpetrados de modo a se realizar massacres cruéis, por meio de disputas políticas e rixas de famílias rivais (PALACÍN, 1994). Note-se que o autor, a despeito de sua origem carioca, passou parte da infância em Catalão, onde morou juntamente com seus avós, no início da década de 1950. O subtítulo do livro, "um faroeste brasileiro", remete-nos a um tema bastante conhecido na cultura ocidental, qual seja o faroeste norte-americano, marcado no imaginário coletivo pelos cowboys e pistoleiros que duelavam entre si pelas ruas de vilarejos e cidades. De fato, Sant'anna constrói a narrativa da história de Catalão valendo-se de um imaginário vinculado ao faroeste dos Estados Unidos sem, no entanto, deixar de representar, em sua narrativa, as peculiaridades do sertão goiano.

Desse modo há, no romance em tela, o retrato da experiência urbana - com referências a cenários rurais - de indivíduos cujas vivências são pautadas por um código de conduta e de honra em que imperam a violência e a lei do mais forte, conforme o qual "um homem só podia ser digno de respeito se exibisse bravura frente aos inimigos e lhes devotasse ódio implacável. Homem que fosse homem jamais poderia levar desaforo para casa por menor que fosse, princípio seguido tanto pelos ricos quanto pelos pobres" (SANT'ANNA, 2012, p. 38). É em razão desse código de honra que grande parte dos habitantes de Catalão comete, em algum momento da narrativa, atos de violência, a fim de demonstrarem sua força, coragem e poder diante de um público que é tanto espectador quanto vítima de tais atos.

Nesse sentido, este artigo tem por finalidade realizar uma leitura de Herança de sangue, tendo como eixo de reflexão a categoria da violência, elemento constituinte da narrativa enfocada, em sua relação simbiótica com o contexto urbano em que a narrativa é ambientada. Para tanto, dividimos o texto em duas seções: na primeira, traçamos um panorama do contexto citadino de Catalão e sua reconfiguração no contexto literário do romance em tela e, na segunda, abordamos a questão da violência, em suas diversas facetas, e o seu desdobramento e consequência no plano da vivência das personagens.

\section{TODAS AS CIDADES, A CIDADE DE CATALÃO}

Conforme discute Renato Cordeiro Gomes, em seu Todas as cidades, a cidade (1994), a representação da cidade em textos se dá por meio de fragmentos e trechos, a partir dos quais o leitor pode ler e interpretar a cidade reconstituída pelo discurso, afirmação que nos remonta a Barthes (1987), para quem a cidade deve ser entendida como uma própria teia discursiva. Na condição de texto, composto por retalhos e configurado a partir de múltiplas perspectivas, a cidade e sua representação são plasmadas de modo desordenado e fragmentário. Nessa perspectiva, a leitura, ou tentativa de leitura da cidade, é uma tarefa árdua que pressupõe um trabalho de construção e reconstrução de sentidos a partir dos fragmentos apresentados no texto em que ela está representada. 
Embora a cidade possa ser, até certo ponto, reconstituída no texto, o discurso é apenas uma tentativa de se representá-la, portanto “jamais se deve confundir uma cidade com o discurso que a descreve”, tal como nos aponta Ítalo Calvino (1990). O texto que a descreve, mesmo compartilhando do caráter confuso e labiríntico das cidades, é apenas uma tentativa de representar a própria urbe, que, por sua vez, nunca será completamente figurada por meio do discurso, até porque, conforme nos aponta Renato Cordeiro Gomes, remontando a Barthes, descrever a cidade "é uma operação poética que procura apreender a escrita da cidade e a cidade como escrita, num jogo aberto à complexidade" (GOMES, 1997, p. 179).

No romance de Sant'anna, Catalão é desvelada aos poucos por meio de um discurso narrativo descontínuo e fragmentado, que vai ganhando forma e se constituindo como tal na medida em que o narrador fornece mais informações a respeito dos acontecimentos, pautados sob a égide da violência, cuja ocorrência acaba por caracterizar a cidade e definir o arriscado modus vivendi de seus habitantes. Ressalte-se o fato de que são poucos os momentos em que o narrador apresenta características físicas da cidade, que é constituída principalmente a partir da descrição de acontecimentos, cujas consequências ficaram marcadas no imaginário coletivo de seus moradores.

Inicialmente, Catalão, originada da época das bandeiras que iniciaram a ocupação de Goiás, era um pouso de tropeiros, "um próspero entreposto, onde os viajantes podiam comprar mantimentos, munição e trocar seus cavalos por outros descansados” (SANT'ANNA, 2012, p. 31), o que nos remete a Mumford (2004), para quem os primeiros núcleos urbanos surgiram principalmente a partir do momento em que os homens sentiram necessidade de abandonar a vida nômade. Com o decorrer do tempo, as cidades foram se tornando um lugar onde se estabeleciam relações interpessoais, as quais eram cada vez mais complexas. Nesse sentido, a origem do antigo pouso de Catalão se aproxima, em certa medida, da origem das primeiras cidades, na medida em que seu surgimento se dá essencialmente pela necessidade que os tropeiros tinham de um lugar onde pudessem estabelecer uma pausa para algum descanso entre suas muitas viagens.

Essa cidade goiana, pouco depois de sua fundação, experimenta um grande surto de prosperidade em virtude do grande número de bandeirantes e expedicionários que ali chegavam, embora esse período de efervescência seja efêmero, findando quando o ciclo do ouro no estado de Goiás entra em declínio. Dessa forma, "o antes movimentado pouso de Catalão virou um lugar esquecido de Deus", onde os moradores "cada vez mais amumiados pela desambição e indolência, voltavam à porta de suas taperas, o rabo de olho na lombada do caminho" (SANT'ANNA, 2012, p. 31-33).

Nesse momento, a imagem de Catalão e de seus habitantes é a da decadência e da desilusão, como se pode notar pelos termos que o narrador utiliza para caracterizar tanto os habitantes, "amumiados", quanto os constituintes físicos da cidade: "taperas". Ignácio, em seu Do campo abandonado para a cidade suportada (2010), salienta que o espaço urbano muitas vezes imprime e toma para si os estados de ânimo das pessoas que nele vivem, o que configura uma ambientação em que o espaço citadino e a vida interna das personagens parecem se fundir. Também aqui, como em muitos outros momentos no romance, a cidade de Catalão comporta características de abandono e marasmo que encontram eco no desleixo e letargia de seus moradores: assim, as personagens esfarrapadas, esquálidas, miseráveis e 
descrentes correspondem às poeirentas ruas da cidade, cenário de genuína desolação.

Essa cidade desolada, cujo desenvolvimento dependia do movimento das bandeiras e das comitivas, agora caminha para o mesmo fim que o da cidade de Zora, criada pela pena de Calvino, que, "obrigada a permanecer imóvel e imutável [...] desfez-se e sumiu. Foi esquecida pelo mundo" (CALVINO, 1990, p. 20). Entretanto, há, para Catalão, uma espécie de redenção, que de certa forma faria grande diferença em sua incipiente vida urbana: por se tratar de um povoado afastado dos grandes centros urbanos, bandidos, pistoleiros e matadores de aluguel, que fugiam de centros mais povoados, eram atraídos para lá.

Dessa forma, a população de Catalão se constitui a partir da chegada cada vez maior de bandidos e fugitivos das cadeias de outras cidades, contribuindo para o aumento da violência no povoado. Assim é que, a cada capítulo, o narrador apresenta personagens responsáveis por criar a imagem violenta da cidade, protagonistas de situações sangrentas que deixavam marcas na memória dos habitantes.

Depois de instantes de promissora prosperidade e franca decadência, Catalão se vê novamente esperançosa com a chegada iminente dos trilhos da ferrovia, que ligaria a cidade a outros importantes núcleos urbanos de Goiás e Minas. Seria a oportunidade de se livrar do marasmo predominante na cidade desde o efervescente ciclo do ouro, pois "a cidade vivia um surto progressista" (SANT'ANNA, 2012, p. 83). No entanto, como pode ser constatado pela leitura do trecho a seguir, a alegria proporcionada pela expectativa do progresso duraria muito pouco:

Com a estrada de ferro já alcançando Araguari, tiveram início os trabalhos de construção do trecho Araguari/Goiandira/Ipameri, com um ramal de Goiandira a Catalão, pequeno apêndice do qual os dirigentes da estrada iriam se arrepender amargamente. Mas, naquele momento, seria impossível imaginar que os turmeiros que dispunham os dormentes e pregavam os trilhos seriam os mesmos que iriam enfrentar, alguns anos mais tarde, o povo da cidade de Catalão, chefiado por Isaac da Cunha, filho de Elyseu, no sangrento episódio do Terceiro Fogo (SANT'ANNA, 2012, p. 87).

Ribeiro (2017, p. 61), ao estudar as figurações do faroeste em dois romances goianos, um deles Herança de sangue, aponta que o narrador desse romance de Sant'anna "prefigura um distanciamento da trama que gera, consequentemente, uma noção de independência dos fatos narrados", isto é, o narrador se isenta de qualquer responsabilidade em relação à narrativa, que apenas a relata, sem causar interferências críticas no decorrer da história.

Entretanto, como explicitado no trecho acima, o narrador, embora se isente dos fatos que narra, lança mão de uma estratégia narrativa interessante, qual seja a de revelar alguns acontecimentos do futuro da narrativa de forma sutil, levando o leitor a pressupor o que está por vir. Assim, quando afirma que os "dirigentes da estrada iriam se arrepender amargamente" e que os turmeiros não imaginavam o que iriam enfrentar, cria uma prolepse (TOMACHÉVSKI, 1978), instigando a curiosidade do leitor e permitindo pressupor que algo ruim acontecerá no futuro e que, consequentemente, afetará o "surto de prosperida- 
de" que a cidade vivia. De fato, em virtude de um episódio chamado de "Terceiro Fogo", a terceira grande manifestação da violência em Catalão, as obras da ferrovia são paralisadas, causando graves consequências ao desenvolvimento daquele núcleo urbano.

Apesar das tentativas de se levar desenvolvimento e progresso à cidade, a violência continuava fazendo parte do dia a dia de seus habitantes. Ao primeiro sinal de fortalecimento comercial e econômico, a lembrança de um crime não resolvido, outro assassinato a sangue frio no centro da cidade, um duelo entre famílias rivais acabava por esfriar a chama de esperança que bruxuleava na cidade.

Segundo Calvino (1990, p. 44), "as cidades [...] são construídas por desejos e medos, ainda que o fio condutor de seu discurso seja secreto, que suas regras sejam absurdas, as suas perspectivas enganosas, e que todas as coisas escondam uma outra coisa". Nesse sentido, se a Catalão representada em Herança de Sangue tem como fio articulador a questão da violência, esta amedronta e fascina parte de seus habitantes, aprisionando-os em uma relação contraditória e enganosa: se, por um lado, desde a fundação da cidade eles testemunhavam todos os tipos de violência, amedrontavam-se em silêncio e igualmente admiravam os autores desses atos violentos, uma vez que tais autores, embora facínoras, também expunham sua bravura, pautada por um código de honra rústico e arcaico. Nesse processo pautado por temor e admiração, os moradores não se davam conta de que essa realidade prejudicava o crescimento de seu núcleo urbano, o qual sempre "foi atrapalhado pela violência de seu povo" (SANT'ANNA, 2012, p. 141).

De acordo com Ignácio (2010, p. 35), a inserção humana em um contexto urbano pode ser, em alguns contextos, paradoxal, uma vez que a mesma cidade que anima, que é um dos motivos de encantamento e esperança para os indivíduos que para ela afluem, é também a cidade que devora seus habitantes, uma vez que "ser habitante da cidade é estar, ao mesmo tempo, protegido e reprimido por suas muralhas invisíveis". A pertinência dessa afirmação é verificada na Catalão de Herança de sangue, que ora anima seus habitantes, acenando-lhes com prenúncios de progresso, ora os desilude, em razão, principalmente, de episódios desdobrados sob a égide da violência, que terminam por adiar tais possibilidades de surtos progressistas.

A despeito, entretanto, da violência e da história sangrenta da cidade, no fim do romance, o narrador, em uma das descrições mais explícitas de Catalão, alude para o fato de que o antigo pouso de tropeiros conseguiu, por bem ou por mal, se constituir como um próspero centro urbano:

Catalão tornou-se uma cidade moderna, com qualidade de vida muito superior à da maioria das capitais brasileiras. Quase não há mendigos nas ruas. Não existem favelas nem bairros miseráveis. Além de faculdades, hotéis e bons hospitais, implantou-se, na saída para Goiandira, um distrito industrial (SANT'ANNA, 2012, p. 183).

Sant'anna configura, em sua narrativa, a imagem de um mosaico, composto por meio de partes de histórias pretéritas, de modo a reconfigurar o espaço citadino mediante um processo discursivo que nos remete ao que Gomes caracteriza como junção de "cacos, frag- 
mentos, rasuras, vazios" (GOMES, 1994, p. 37), ao aludir ao modo como as cidades, em toda sua dinâmica, são representadas textualmente.

Ao ter sua história plasmada pela pena de Sant'Anna, Catalão se deixa ler como mais uma urbe, na medida em que sua racionalidade geográfica e humana é a mesma de muitas outras cidades, com suas ruas, becos, casas, estabelecimentos comerciais, espaços de convivência e discordâncias, mas suas peculiaridades, permeadas por acontecimentos trágicos e traumatizantes, posto que extremamente violentos, fazem com que ela se distinga de outras tantas cidades existentes. Nesse sentido, a Catalão de Herança de Sangue é, de todas as cidades, a cidade.

\section{VIOLENNCIA EM HERANÇA DE SANGUE: FOGOS QUE ARDEM NO CERRADO}

Herança de Sangue apresenta uma estrutura que o aproxima do texto jornalístico, pois a narrativa é rápida e dinâmica, o que acaba por entabular um diálogo com o próprio enredo, o qual apresenta personagens fortes e ativas. A história é tributária do resgate e registro de relatos orais dos próprios moradores da cidade, colhidos por Sant'Anna em razão de sua proximidade com a cidade, na condição de seu ex-morador. Além dos depoimentos, ele também trabalha com extensa bibliografia sobre a cidade, fotos, documentos e um blog. Desse modo, seu romance apresenta uma narração do período de formação de Catalão com base em extensa pesquisa encadeada e organizada em forma de enredo, o qual é apresentado em parágrafos curtos, distante das descrições pormenorizadas e de cunho realístico.

Em termos estruturais, o romance é organizado em vinte e um capítulos, dentre os quais apenas o primeiro, intitulado "Domingo, 16 de agosto de 1936", não se insere em uma ordem cronológica. Esse capítulo constitui um tipo de prolepse implícita, visto que se narra o linchamento de um homem inominado, e o último capítulo, intitulado "A longa noite dos punhais", retoma a narração desse episódio, quanto os leitores se inteiram do fato de que se tratava do linchamento do farmacêutico e poeta Antero da Costa Carvalho, personagem já apresentada em outros capítulos, e que fora preso por supostamente ser o mandante da tocaia para o fazendeiro Albino Felipe. Dentre os vários assassinatos por tocaia, vingança, disputa de poder local ou por simples desentendimento, este merece atenção especial pela brutalidade praticada neste dia marcante na história da cidade.

Os demais capítulos, com exceção de quatro, se destinam a apresentar relatos de personagens cuja história, pautada por um violento código de honra, é contada. Os outros quatro capítulos são intitulados de "Primeiro Fogo", "Segundo Fogo", “Terceiro Fogo" e "Quarto Fogo", nos quais se narram momentos em que atos criminosos e violentos atingem concomitantemente uma parcela maior de pessoas, configurando verdadeiras batalhas coletivas, travadas pela lâmina de facas, facões e machados e pelo cano de revólveres e cartucheiras.

Interessante notar que a infeliz e trágica história de Antero abre e fecha a narrativa, demonstrando pelo menos dois fatos: o de que o enredo da obra obedece a um movimento cíclico, em que a violência impera e aprisiona a existência humana, e o de que a "[...] fama, em Catalão, era coisa para pistoleiros. Gente que sabia defender, à bala, sua reputação. Não para janotas que falavam macio, recitavam poesias e conseguiam ganhar dinheiro numa época de tanta miséria." (SANT’ANNA, 2012, p. 150), ou seja, o sucesso comercial da farmá- 
cia de Antero, suas poesias, sua amizade com muitos, acabaram por lhe resultar na própria morte, embora tenha sido, como se constará, que foi a partir de sua morte que muitos habitantes da cidade puderam repensar seu modo de agir, e começaram a conhecer contornos de um sentimento do qual, até então, não se havia tido registro na cidade: o remorso.

De acordo com Nilo Odalia (1983, p. 13), "viver em sociedade foi sempre um viver violento". Nesse sentido, a violência está presente no meio social desde o surgimento da humanidade e, por isso, está incorporada diretamente à vivência humana individual e coletiva, configurando-se, a literatura, como uma das expressões em que crimes perpetrados com violência e crueldade se tornam material narrado, de modo a reconstituir a história tanto individual quanto de determinados grupos sociais.

No caso da Catalão representada em Herança de Sangue, a lei escrita não era respeitada, de modo que imperava um código de honra - conhecido como a Lei de Catalão - que fazia com que os habitantes vivenciassem momentos de tensão enquanto assistiam à luta pelo poder, travada entre coronéis que não hesitavam quando queriam impor respeito e temor. Dessa maneira, a vivência urbana dos indivíduos catalanos era pautada por esse código de conduta, segundo o qual a violência era sinônimo de poder e bravura. Mais que isso: a existência desse código implicava questões que extrapolavam a luta pelo poder. A honra e o respeito só eram conseguidos na cidade por quem fosse destemido o suficiente para resolver suas questões "à bala ou à faca", já que "um homem nascido em Catalão podia até dever dinheiro. Honra, jamais. E honra só se pagava com sangue” (SANT’ANNA, 2012, p. 91).

Observe-se nesse aspecto que o autor, ao tomar como fio condutor do romance a violência presente nessa urbe, acaba por realçar uma das peculiaridades que diferenciam essa cidade de outros aglomerados urbanos, pois verifica-se, na massa verbal da narrativa, que a brutalidade e a selvageria presentes na cidade tornam-se um aspecto constitutivo da identidade de seu povo, o qual sente que sua urbe não era qualquer cidade: "Catalão era Catalão, lugar de gente braba e boa de tiro" (SANT’ANNA, 2012, p. 68). Talvez por isso o narrador se esmere tanto ao utilizar a locução adjetiva "de Catalão" para caracterizar os moradores-personagens, cuja principal característica era, simplesmente, serem de Catalão.

Alguns historiadores confirmam em seus estudos o caráter violento da cidade goiana, alguns de cujos habitantes perpetravam atos bárbaros e violentos em busca de respeito, poder e honra. Oliveira (2012, p. 19), ao estudar a violência no estado de Goiás, reitera que "Catalão, um lugar de fronteira, desde o início de sua história, foi marcado pela violência", ao passo que Silva (2014, p. 27) nos alerta para o fato de que "é comum ouvir dos moradores mais antigos da cidade de Catalão-GO que ela carrega em sua história uma saga de sangue".

Nesse sentido, a manutenção da honra também implicava ser valente e hábil no manejo de armas e ter a "braveza de macho", característica que nivelava toda a população da cidade: “nem janotas nem roceiros temiam cara feia ou bala” (SANT'ANNA, 2012, p. 57). Dessa forma, a violência, circunstanciada no romance analisado muitas vezes pela inveja, pela vingança, pela busca pelo poder, pela manutenção da honra e da reputação, era vista no sertão como sinal de hombridade e valentia (IGNÁCIO, 2010).

Embora a violência esteja presente na narrativa do início ao fim, de maneira a simbolizar talvez a onipresença dela na história da cidade de Catalão, os momentos em que a violência extrapola os limites urbanos são chamados pelo narrador de "Fogos". É interessante 
ressaltar que o fogo da violência na cidade é constante: suas chamas, embora mais fracas durante certos períodos, queimam ininterruptamente, fazendo vítimas e contribuindo para a construção de uma memória coletiva pautada, contraditoriamente, no medo e na excitação perante a violência dos atos praticados.

Ainda povoado, Catalão já testemunhava diferentes tipos de violência: "conflitos, motivados por ódios familiares, por ofensas (reais ou imaginárias) e pelas razões mais fúteis, estouravam quase que diariamente" (SANT'ANNA, 2012, p. 37). Além disso, a própria constituição da população da cidade, composta por muitos bandidos e fugitivos de cadeias de cidades vizinhas, contribuía para a eclosão de tantos conflitos. Esse contexto violento, plasmado pelo narrador durante os primeiros capítulos, culmina no "Primeiro Fogo", qual seja a primeira grande manifestação de violência nas ruas da cidade.

Esse episódio é narrado no capítulo 6, durante o qual o narrador se utiliza da estratégia de contextualizar não só a realidade de Catalão como também a realidade do país e do mundo, fornecendo informações a respeito dos acontecimentos marcantes ao redor do mundo para, depois, relacioná-los ao contexto social catalano. Dessa forma, "o narrador elabora contrapontos entre os avanços sociais e culturais da humanidade diante de casos particulares de Catalão" (RIBEIRO, 2017, p. 65), mediante uma estratégia que evidencia o descompasso histórico e cultural que essa cidade vivenciava à época.

O conflito que desencadeou o "Primeiro Fogo" fora puramente baseado na rivalidade entre as famílias Ayres e Paranhos, que detinham o poder local e cujas rusgas, mais cedo ou mais tarde, irromperiam de forma trágica:

O que se esperava acabou acontecendo. Exatamente às dez da manhã de sexta-feira, dia 16 de dezembro de 1892, iniciou-se o Primeiro Fogo de Catalão. Nessa hora, alguns tiros foram disparados da casa do capitão Andrade, em direção ao sobrado Paranhos [...] A resposta não se fez esperar. O tiroteio durou uma hora (SANT'ANNA, 2012, p. 63).

O tiroteio durou apenas uma hora, pouco tempo considerando-se a grande duração de outros que posteriormente são retratados na narrativa, e resultou em poucas mortes: a "de um jagunço, bem aceita pelos dois lados, pois não ficava bem, em Catalão, tanto tiro e nenhum defunto" (SANT’ANNA, 2012, p. 64). Por fim, a família Paranhos se rende, ironicamente, por causa de uma crise nervosa da esposa do coronel.

A vingança, também, fazia parte da Lei de Catalão, uma vez que muitos são os momentos na narrativa em que uma ou outra personagem lança mão da violência a fim de se vingar por algum ente familiar assassinado, pois "nada mais natural do que vingar a morte de um parente. Chegava a ser obrigação da família do morto” (SANT’ANNA, 2012, p. 80).

O "Segundo Fogo" acontece justamente em razão da vingança. Os Paranhos, sentindo-se envergonhados pela rendição forçada no "Primeiro Fogo", voltam à cidade com apoio do governo do estado e incitam diretamente o capitão Andrade, grande rival dos Paranhos. Ao contrário do conflito anterior, o "Segundo Fogo" dura dois dias de intenso tiroteio e resulta na morte do coronel Antônio Paranhos e na fuga desesperada do capitão Andrade: 
Atingido por três balaços, um de cada atirador, o coronel dobrou os joelhos e tombou. Mas logo fez um esforço para se erguer. Nesse momento, outros dois tiros o acertaram. Um deles secionou sua femoral. Em segundos, o senador morreu, em meio a uma pasta de terra e sangue. [...] A fuzilaria durou quinze minutos. Seguiu-se profundo silêncio. Catalão parou de respirar (SANT’ANNA, 2012, p. 70-71).

Verifica-se, pela leitura do excerto apresentado, um tipo de simbiose entre a personagem que morre e a cidade que lhe assiste à morte, o que perfaz o que Tomachévski (1978) conceitua como "motivação caracterizadora homóloga", ou seja, quando se nota uma relação de homologia entre o espaço retratado e as personagens que nele agem. Como num lance cinematográfico, à morte do coronel Paranhos corresponde uma cidade que, naquele momento, também parou de respirar.

Nesse trecho, também se verifica que o sangue do coronel se junta à terra de Catalão, tornando ambos um só. Durante todo o romance, o narrador relaciona os momentos de maior tensão e manifestação da violência com a cor vermelha, criando uma ambientação que pouco a pouco aponta para fatos que estão por acontecer e construindo, a cada capítulo, a herança de sangue da cidade goiana, representada pelo vermelho sempre presente na narrativa.

Note-se a esse respeito que, inicialmente, o vermelho está presente como algo exterior à cidade: "quando a bola vermelha do sol de inverno se escondeu no horizonte, na direção de Goiandira, quase deu para perceber o instante exato em que a noite chegou a Catalão" (SANT'ANNA, 2012, p. 21). Na metade da narrativa, no entanto, a cor vermelha já se reflete na cidade por meio da "vermelhidão da madrugada" (SANT'ANNA, 2012, p. 100) e, nos capítulos finais, o vermelho, que terminou por se fundir ao sangue, já está impregnado nas filigranas que plasmam a existência humana em Catalão.

O episódio do “Terceiro Fogo" acontece também em virtude de uma vingança. Entretanto, como lembra Ribeiro (2017), nesse caso, a vingança não é pessoal, mas sim coletiva, na medida em que grupos políticos opostos e toda a população da cidade se unem com o objetivo de vingar o assassinato, pelas mãos de alguns forasteiros que estavam na cidade em razão da construção da ferrovia, de Emerenciana Neiva, amante ao mesmo tempo do delegado da cidade, comumente chamado Suã de Vaca, e do "mandachuva" da cidade, Isaac da Cunha. O narrador cria a tensão do evento a ser narrado a partir de uma prosopopeia, fazendo com que até as máquinas presenciem e temam a violência de Catalão:

Faltavam alguns minutos para as cinco e meia quando o comboio passou pela estação e deixou a cidade, as rodas batendo de maneira cadenciada nas junções dos trilhos. A locomotiva percorreu uma pequena reta e se aproximou da curva, apitando de maneira desconfiada, como se a própria máquina pressentisse a emboscada (SANT'ANNA, 2012, p. 100).

A locomotiva pressente o perigo; talvez ela, desconfiada, faça uma contraposição ao estado de espírito dos trabalhadores da ferrovia, entre eles mulheres e crianças, que inocen- 
temente apenas esperavam pelo amanhecer para iniciarem seus trabalhos. Depois de pouco menos que quinze minutos de tiroteio, nove turmeiros, como eram chamados os trabalhadores, morreram, entre os quais duas crianças. Assim, a violência narrada em Herança de sangue adquire um certo caráter democrático, como discute Odalia (1983), uma vez que atinge a todas as pessoas, independentemente de gênero, idade, raça, religião.

Ao contrário dos três Fogos anteriores, o quarto e último Fogo de Catalão se dá em razão de alguém sentir necessidade de se mostrar forte e valente perante a população da cidade. Com esse objetivo, João Sampaio assassina o intendente municipal Salomão de Paiva, o que propicia algo inusitado, uma vez que "na história de Catalão, poucos enterros foram tão concorridos quanto o de Salomão de Paiva” (SANT’ANNA, 2012, p. 129).

Em relação a de Antero Carvalho, cujo assassinato já foi mencionado quando apresentamos o enredo do romance em tela, cumpre observar que se tratava de um "prático de farmácia e vinha de Campo Grande, Mato Grosso, trazido por uma síria de nome Amélia Nazar, dez anos mais velha do que ele. Amélia tinha pais e irmãos em Catalão" (SANT'ANNA, 2012, p. 148). Assim que chega em Catalão, ele começa a se popularizar pela delicadeza de suas ações, já que realizava consultas médicas aos mais pobres e doava alguns remédios, vindo a se tornar grande amigo de Albino Felipe, antigo fazendeiro da região. Entretanto, com o assassinato misterioso de Albino, a história de Antero tem uma guinada radical, uma vez que ele se torna o principal suspeito do assassinato do amigo.

Em razão dessa suspeita é que, na noite do dia 16 de agosto de 1936, um domingo, após grande martírio pelas ruas da cidade, já manchadas pelo sangue dos antigos moradores assassinados, Antero é apunhalado coletivamente ao ser "condenado" pelo chefe político de Catalão por um crime que, ao que tudo indica, não havia perpetrado. Se, com a morte de um antigo chefe político local a urbe havia deixado de respirar, conforme já mencionamos, com o linchamento de Antero Carvalho a cidade faz silêncio, uma vez que os gritos do poeta assassinado ecoavam na lembrança dos moradores da cidade, sendo em razão da morte dele que "uma imensa culpa coletiva se apoderou de Catalão" (SANT'ANNA, 2012, p. 176). Depois da longa noite dos punhais, "Catalão nunca mais foi a mesma" e "passou a se envergonhar de sua saga de sangue" (SANT'ANNA, 2012, p. 183-184), assim como seus habitantes, que sentiam um "aperto fundo de arrependimento".

\section{CONSIDERAÇÕES FINAIS}

Herança de sangue apresenta uma narrativa em que as personagens têm vida efêmera, posto que são vitimadas pela violência que, oriunda de individualidades, acaba por plasmar os contornos simbólicos de todo um espaço urbano, tornando-se, ela mesma, também personagem. Também se verifica que, se por um lado essa violência exacerbada assusta e amedronta uma certa parcela da população local, por outro lado é em virtude dessa mesma exacerbação que a história individual e coletiva do povo de Catalão vai se formando e se consolidando fixamente na memória urbana coletiva, por meio de cujo compartilhamento tem-se o enredo do romance de Sant'Anna.

Percebe-se que as crônicas dos antigos habitantes de Catalão, reconstituídas pelo 
discurso de um narrador que tenta se isentar ao máximo em relação à crueldade dos eventos narrados, constituem um registro mnemônico que também permite entrever a caracterização da cidade como local de pouso e depois centro urbano, o que se dá a partir de experiências e acontecimentos típicos do sertão e de ambientes rurais. A própria visão positiva da violência e da valentia, por parte dos catalanos cuja vida se deixa retratar na obra, aponta, como se pôde observar, para valores prezados por habitantes de antigos meios rurais, mas que, em Catalão, se radicalizam na condição de culto ao valente, por mais que sua valentia resulte de uma natureza implacável e resulte em assassinatos bárbaros e horripilantes.

Esse fato implica diretamente a vivência das personagens que tem suas vivências pautadas, ao mesmo tempo, pela violência e pela euforia que ela proporciona, bem como pelos surtos de desenvolvimento e modernização que hora ou outra dinamizam a cidade. Dessa forma, tanto o espaço citadino quanto as interações humanas que nele se realizam concorrem para a formação da crônica histórica da cidade, um espaço sertanejo e violento, embora a modernidade já comece a prenunciar seu futuro, que se pautará inclusive por "qualidade de vida muito superior à da maioria das capitais brasileiras” (SANT’ANNA, 2012, p. 183).

Não obstante essa observação do autor, ainda atualmente "as famílias da cidade não aceitam ter seus nomes ligados ao linchamento [de Antero Carvalho]" (SANT'ANNA, 2012, p. 182). Talvez porque não haja desenvolvimento econômico e qualidade de vida contemporâneas que possam apagar, por completo, as reminiscências urbanas primeiras de Catalão, lembranças que dão forma não apenas a fatos pretéritos, mas que também se configuram como corolário de crimes, assassinatos e linchamentos que, em seu conjunto, se traduzem, para os descendentes das primeiras famílias catalanas, em uma verdadeira herança de sangue.

\section{REFERÊNCIAS}

BARTHES, Roland. Semiologia e urbanismo. In: BARTHES, Roland. A aventura semiológica. Trad. Maria de Santa Cruz. Lisboa: Edições 70, 1987. p. 110-157.

CALVINO, Ítalo. As cidades invisíveis. Trad. Diogo Mainardi. São Paulo: Companhia das Letras, 1990.

GOMES, Renato Cordeiro. Todas as cidades, a cidade: literatura e experiência urbana. Rio de Janeiro: Rocco, 1994.

IGNÁCIO, Ewerton de Freitas. Do campo abandonado para a cidade suportada: campo e cidade na literatura brasileira. Anápolis: Universidade Estadual de Goiás, 2010.

MUMFORD, Lewis. A cidade na história. 4. ed. São Paulo: Companhia das Letras, 2004.

ODALIA, Nilo. O que é violência. 2. ed. São Paulo: Editora Brasiliense, 1983. 
OLIVEIRA, Eliézer Cardoso. Chacinas, combates e massacres: medo e violência em Goiás. Goiânia: PUC-GO; Kelps, 2012.

PALACÍN, Luis. História política de Catalão. Goiânia: Ed. UFG, 1994. (Coleção Documentos Goianos)

RIBEIRO, Raphael Martins. FAR-CENTRO-OESTE: fronteiras e figurações do faroeste em Herança de sangue e Cidade livre. Dissertação (Mestrado em Ciências Sociais e Humanidades). Anápolis: Universidade Estadual de Goiás, 2017. Disponível em: < https://sucupira.capes.gov.br/sucupira/public/ consultas/coleta/trabalhoConclusao/viewTrabalhoConclusao.jsf?popup=true\&id_trabalho=5016911 $>$. Último acesso: 19 de agosto de 2019.

SANT’ANNA, Ivan. Herança de sangue: um faroeste brasileiro. São Paulo: Companhia das Letras, 2012.

SILVA, Jaciely Soares da. Violência e Religiosidade Popular em Catalão-GO: a construção da santidade de Antero 1932-2012. Dissertação (Mestrado em História) Universidade Federal de Uberlândia: Uberlândia, 2014. Disponível em: < https://repositorio.ufu.br/bitstream/123456789/16478/1/ ViolenciaReligiosidadePopular.pdf >. Último acesso: 19 de agosto de 2019.

TOMACHEVSKI, Boris. Temática. In: Formalistas russos. Porto Alegre: Globo, 1978. 